\title{
Systemic Sclerosis is Not Associated with Increased Coronary Artery Calcium Deposition
}

\author{
Sistemik Sleroz Artmış Koroner Arter Kalsiyum Birikimi ile İlişkili Değildir
}

\author{
Lee SEUNG-GEUN, ${ }^{2}$ Park YOUNG-EUN,${ }^{1}$ Choi SU-YEON, ${ }^{3}$ Park EUN-KYUNG, ${ }^{2}$ \\ Kim GEUN-TAE, ${ }^{4}$ Choo KI-SEOK, ${ }^{5}$ Jeong YEON-JOO ${ }^{6}$ \\ ${ }^{1}$ Biomedical Research Institute, Pusan National University Hospital, Busan, Korea (South) \\ ${ }^{2}$ Department of Internal Medicine, Division of Rheumatology, Pusan National University School of Medicine, Busan, Korea (South) \\ ${ }^{3}$ Department of Internal Medicine, Division of Rheumatology, Healthcare System Gangnam Center, \\ Seoul National University Hospital, Seoul, Korea (South) \\ ${ }^{4}$ Department of Internal Medicine, Division of Rheumatology, Kosin University College of Medicine, Busan, Korea (South) \\ ${ }^{5}$ Department of Radiology, Pusan National University Yangsan Hospital, Yangsan, Korea (South) \\ ${ }^{6}$ Department of Radiology, Pusan National University Hospital, Busan, Korea (South)
}

Objectives: This study aims to compare the coronary artery calcium scores (CACS) between female systemic sclerosis (SSc) patients and healthy subjects and to investigate whether SSc alone is an independent risk factor for increased coronary artery calcium deposition.

Patients and methods: Between January 2007 and December 2009, 41 female SSc patients and 123 age- and gender-matched healthy subjects who were admitted to a tertiary healthcare center in South Korea were retrospectively analyzed. The CACS were measured using multidetector computed tomography (MDCT) and categorized as either absent $(C A C S=0)$, minimalto-mild (CACS $=1-100$ ), or moderate-to-severe (CACS $\geq 101$ ). We also collected data from each patient related to conventional cardiovascular risk factors.

Results: There was no significant difference in the CACS and the proportion of minimal-to-mild and moderate-to-severe coronary calcium deposition between the two groups $(p=0.519$ and $p=0.242$, respectively). Multivariable logistic regression analysis revealed that SSc was not independently associated with the presence of coronary calcium deposition (CACS $>0$ ) after confounding factors were adjusted. Although SSc was more likely to have a higher category of CACS in the multivariable ordinal logistic regression model (OR 2.79, 95\% Cl 0.92-8.49, $\mathrm{p}=0.07$ ), this did not reach statistical significance. Among traditional risk factors, only older age was significantly associated with increased coronary calcium deposition.

Conclusion: Our study results suggest that SSc is not an independent risk factor for atherosclerosis.

Key words: Atherosclerosis; coronary artery; multi-detector computed tomography; systemic scleroderma.
Amaç: Bu çalışmanın amacı kadın sistemik skleroz (SSc) hastaları ve sağlıklı kişiler arasında koroner arter kalsiyum skorlarını (KAKS) karşılaştırmak ve SSc'nin tek başına artmış koroner arter kalsiyum birikimi için bağımsız bir risk faktörü olup olmadığını araştırmaktır.

Hastalar ve yöntemler: Ocak 2007 ve Aralık 2009 tarihleri arasında Güney Kore'de üçüncü basamak bir sağlık merkezine başvuran 41 kadın SSc hastası ile yaş ve cinsiyeti eşleştirilmiş 123 sağlıklı kişi retrospektif olarak incelendi. Koroner arter kalsiyum skorları multidedektör bilgisayarlı tomografi (MDBT) ile ölçüldü ve skorlar yok (KAKS=0), minimum-hafif (KAKS=1$100)$ veya orta-şiddetli (KAKS $\geq 101)$ olarak sınıflandırıldı. Ayrıca her hastadan konvansiyonel kardiyovasküler risk faktörlerine ilişkin veri alındı.

Bulgular: Koroner arter kalsiyum skoru ile minimum-hafif ve orta-şiddetli koroner kalsiyum birikiminin birbirine oranı açısından iki grup arasında anlamlı bir fark yoktu (sırasıyla $p=0.519$ ve $p=0.242$ ). Çok değişkenli lojistik regresyon analizi, karıştırıcı faktörler ayarlandıktan sonra, SSc'nin koroner kalsiyum birikimi (KAKS>0) ile bağımsız olarak ilişkili olmadığını gösterdi. Çok değişkenli sıralı lojistik regresyon modelinde, SSc'nin KAKS kategorisi daha yüksek olmasına karşın (OR 2.79, 95\% Cl 0.92-8.49, p=0.07), istatistiksel anlamlılığa ulaşmadı. Geleneksel risk faktörleri arasından yalnızca ileri yaş artmış koroner kalsiyum birikimi ile anlamlı düzeyde ilişkili bulundu.

Sonuç: Çalışma bulgularımız SSc'nin ateroskleroz için bağımsız bir risk faktörü olmadığını göstermektedir.

Anahtar sözcükler: Ateroskleroz; koroner arter; multidedektör bilgisayarlı tomografi; sistemik skleroderma.

Received: April 28, 2013 Accepted: July 10, 2013

Correspondence: Choi Su-Yeon, M.D. Department of Internal Medicine, Division of Cardiology, Healthcare System Gangnam Center, Seoul National University Hospital, 737 Yeoksam-dong, Gananam-Gu, 135-984, Seoul, South Korea.

Tel: +82-2-2112-5639 e-mail: sychoi9@gmail.com

(O2013 Turkish League Against Rheumatism. All rights reserved. 
Systemic sclerosis (SSc) is a connective tissue disease of unknown etiology which is characterized by widespread fibrosis of the internal organs and diffuse vascular lesions. The microvasculature, the part of the circulatory system made up of arterioles, capillaries, and venules, is recognized as the main target of vasculopathy in SSc. ${ }^{[1]}$ Although the pathogenesis of microvascular involvement has not yet been fully elucidated, a growing body of evidence suggests that endothelial dysfunction, which impairs vasomotor regulation, could be a major contributor toward the vasculopathy in patients with SSc. ${ }^{[1,2]}$ In addition, because endothelial dysfunction can promote or exacerbate atherosclerosis via microvessel wall damage, ${ }^{[3]}$ a large amount of attention has recently focused on macrovascular disease owing to atherosclerosis in SSc. ${ }^{[4,5]}$

Atherosclerosis, the leading cause of death in developed countries, is now considered to be an inflammatory process. ${ }^{[6]}$ Accelerated atherosclerosis with premature death rates has been well documented in other inflammatory rheumatic diseases such as rheumatoid arthritis (RA) and systemic lupus erythematosus (SLE). ${ }^{[7,8]}$ Sustained synovial inflammation and the subsequent overproduction of C-reactive protein (CRP) can enhance atherosclerosis in RA, and antiphospholipid antibodies play a substantial atherogenic role in SLE. ${ }^{[8]}$ While death rates due to premature atherosclerotic cardiovascular and cerebrovascular diseases in patients with SSc have consistently increased in recent decades, ${ }^{[9]}$ the prevalence of atherosclerotic coronary disease in SSc patients has not yet been determined. ${ }^{[10,11]}$ Among various methods to evaluate atherosclerotic coronary artery disease (CAD), the coronary artery calcium score (CACS), which is generated by multidetector computed tomography (MDCT), can be used as a surrogate marker for coronary atherosclerosis. ${ }^{[6]}$ In particular, MDCT is considered to be an important and promising technique for evaluating atherosclerotic CAD due to its high diagnostic accuracy and usefulness for predicting major cardiac outcomes. ${ }^{[12-15]}$ To date, two previous studies showed that coronary calcium deposition, as identified by MDCT, is significantly more extensive in SSc patients than in healthy controls. ${ }^{[16,17]}$ However, the small number of reports warrants further exploration of the prevalence of coronary atherosclerosis, as determined by MDCT. In patients with SSc and points out the need to ascertain the results from previous studies.

In the present study, we compared the frequency of coronary atherosclerosis, as evaluated by MDCT, between female SSc patients and age- and gendermatched healthy subjects and corroborated the hypothesis regarding whether SSc per se is an independent risk factor for increased coronary artery calcium deposition.

\section{PATIENTS AND METHODS}

\section{Study design and participants}

In this retrospective study, 41 female patients with SSc and 123 age- and gender-matched healthy subjects (2070 years old) were evaluated, and the medical records of all of the participants, who had been admitted to a tertiary hospital in South Korea between January 2007 and December 2009, were reviewed. Because of the limited number of male patients with SSc at our center, we analyzed only female participants, and all of these met the preliminary classification criteria of the American College of Rheumatology for SSc. ${ }^{[18]}$ The following SSc patients were excluded from our study: (i) those who had a history of preexisting cardiovascular diseases, including CAD and stroke; (ii) those with rheumatic diseases other than SSc; (iii) pregnant patients; and (iv) those who refused to participate in the study. Healthy subjects with no history of cardiovascular or rheumatic diseases were randomly selected from applicants for an annual health check and were matched for age and gender at a 3:1 ratio to the patients with SSc. For the age matching, the SSc patients and healthy subjects were matched by year of birth. If no appropriately matched healthy subject was found, this age-matching criterion was expanded stepwise in age increments or decrements of one year to a maximum of three years. ${ }^{[19]}$ In addition, to minimize the effect of lipid, blood pressure, or glucoselowering agents and smoking status on coronary artery calcium deposition, those participants taking these medications were also excluded from the study along with both current and past smokers. This study was approved by the Research and Ethics Review Board of the Pusan National University Hospital, Busan, South Korea, which waived the need for informed patient consent (E-2012099).

\section{Assessments}

We reviewed the anthropometric parameters of all subjects, including height, weight, body mass index (BMI), and waist circumference. Height and weight were measured using an inflexible portable measuring bar and a portable electronic weighing scale, respectively. Body mass index was calculated by dividing the body weight by the square of height in 
meters $\left(\mathrm{kg} / \mathrm{m}^{2}\right)$, and waist circumference was measured midway between the iliac crest and the lowermost margin of the ribs on the mid-axillary line at the end of a normal expiration using a flexible steel tape. Blood pressure was determined as the average of two measurements obtained 10 minutes apart after the study subjects had rested for at least 10 minutes using a TM-2655P fully automatic blood pressure monitor (A\&D Company, Limited, Tokyo, Japan). Furthermore, hypertension (HT) was diagnosed in participants with a blood pressure of $\geq 140 / 90 \mathrm{mmHg}$ and in those who were taking antihypertensive medications.

The SSc patients were classified as having limited SSc or diffuse SSc based upon the distribution of skin involvement according to the methods proposed by LeRoy et al. ${ }^{[20]}$ Internal organ involvement was evaluated in the SSc patients by determining the presence of interstitial lung disease (ILD) via highresolution computed tomography (HRCT) performed concurrently with the MDCT. In addition, pulmonary arterial hypertension (PAH) was defined as having a pulmonary arterial pressure (PAP) of $>35 \mathrm{mmHg}$ on at least two occasions as measured by color Doppler echocardiography. Additionally, a diagnosis of gastrointestinal involvement was based on clinical symptoms such as reflux esophagitis requiring a proton pump inhibitor, dysphagia, or small bowel bacterial overgrowth while skin involvement was determined according to the modified Rodnan skin score (mRSS) ${ }^{[21]}$ as measured by a rheumatologist. The current medications of all patients with SSc [e.g., penicillamine, cyclophosphamide, vasodilators, anti-platelet agents, and glucocorticoids (GCs)] were recorded, and the cumulative GC doses were calculated by multiplying the current daily dose by the number of days for which the patients had taken them since they were first prescribed.

We also reviewed the fasting serum glucose levels and concentrations of total cholesterol (TC), highdensity lipoprotein cholesterol (HDL-C), triglycerides (TGs) and low-density lipoprotein cholesterol (LDL-C). The fasting serum glucose levels were assessed using the glucose oxidase method with a Synchron LX20 chemical analyzer (Beckman Coulter, Inc., Fullerton, USA) while the concentrations of TC, HDL-C, and TGs were measured with an enzymatic colorimetric reagent (Roche Diagnostics, Basel, Switzerland) on a P800 Modular Chemical Analyzer (Roche Diagnostics, Basel, Switzerland). The LDL-C was then calculated using the Friedewald equation. For the SSc patients, the erythrocyte sedimentation rate (ESR), CRP, and autoantibody profiles, including the antinuclear antibody (ANA), anticentromere antibody (ACA), and anti-topoisomerase I (anti-SCL-70) were also measured. The CRP was analyzed using a particleenhanced immunoturbidimetric assay (Tina-quant C-reactive protein, Roche Diagnostics, Switzerland), and the ANA and ACA were assessed via indirect immunofluorescence on HEp-2 cells (cut-off value: 1:40) while the anti-SCL-70 was determined using immunoblot testing (EUROLINE anti-ENA profile 1).

\section{Coronary artery calcium score}

All participants underwent CT scanning via a SOMATOM Sensation 16-eco MDCT (Siemens AG, Erlangen, Germany), and the following CT protocols were used: $16 \times 0.75-\mathrm{mm}$ collimation, tube voltage of $120 \mathrm{kV}$, pitch 0.2 , gantry rotation time 0.37 seconds, and image reconstruction thickness/interval of $3 \mathrm{~mm} / 3 \mathrm{~mm}$. The images were reconstructed at $3 \mathrm{~mm}$ thickness using retrospective electrocardiographic gating. The CACS in the left main coronary artery, left anterior descending artery, left circumflex artery and right coronary artery were assessed using the Open Communication Wizard program Simens 16 (Siemens AG, Erlangen, Germany) by a single radiologist who was blinded to the information about the participants. Coronary calcium deposition was categorized as either absent $(\mathrm{CACS}=0$ ), minimal-to-mild (CACS 1-100), or moderate-to-severe (CACS $\geq 101){ }^{[22]}$

\section{Statistical analysis}

Values were expressed as mean \pm standard deviation, median (minimum, maximum) or number of cases with percentages, as appropriate. For group comparisons, we used the two-tailed Student's t-test or the Mann-Whitney U test for continuous variables and the chi square test or the Fisher's exact test for categorical variables, as appropriate. The KolmogorovSmirnov test was also applied to assess the distribution of each continuous variable. Comparing the CACS between the SSc patients and healthy subjects was our primary goal. However, because the distributions of the CACS in both groups were markedly skewed to the left (CACS $=0$ for most subjects), such types of distributions were not easy to describe in a comprehensive manner with conventional methods, such as medians and percentiles (the median values of both groups were zero). Thus, we depicted the CACS of the two groups using cumulative probability plots as proposed by Landewe et al. ${ }^{[23]}$ to improve comprehensibility. In addition, to analyze the independent association of SSc with coronary artery calcification, we performed 
multivariable logistic regression using CACS $>0$ as an dependent variable and a multivariable ordinal logistic regression analysis, which modeled the probability of being in a higher category of coronary artery calcification $(\mathrm{CACS}=0,1-100, \geq 101)$, using a stepwise model selection of variables with a $p$ value $\leq 0.1$ in univariate analysis. The odds ratios (ORs) with 95\% confidence intervals (CI) were also calculated to assess the association between the variables and coronary calcium deposition. $P$ values of $<0.05$ were considered to be significant, and all statistical analyses were performed using the STATA version 11.1 for Windows software program (StataCorp LP, College Station, TX, USA).

\section{RESULTS}

The clinical characteristics of the patients with SSc are shown in Table 1 . Twenty patients $(48.8 \%)$ had limited SSc while 21 (51.2\%) had diffuse SSc. The mean age of SSc patients was 50.1 years, and the median disease duration was six years. The majority of the patients had ILD on HRCT and gastrointestinal involvement. No differences in the percentages of ILD, PAH, and gastrointestinal involvement were observed between the limited and diffuse SSc patients. The mean mRSS for all of the SSc patients was 13, but the mRSS was significantly higher in the diffuse SSc patients $(p<0.001)$. While the proportion of the subjects who were taking GCs was similar between the limited and diffuse SSc patients, the cumulative GC dosage tended to be higher in the diffuse SSc patients $(p=0.057)$.
Antinuclear antibodies were present in all of the patients, and the proportion of patients with positive anti-SCL-70 was significantly higher in the diffuse SSc patients than in those with limited SSc $(p<0.001)$. However, there was no difference in the percentage of ACA positivity between the limited and diffuse SSc patients.

Table 2 shows the comparisons between the conventional cardiovascular risk factors and CACS with regard to the SSc patients and the age- and gender-matched healthy subjects. In the SSc patients, the serum glucose $(\mathrm{p}<0.001), \mathrm{LDL}-\mathrm{C}(\mathrm{p}=0.006)$, HDL-C $(\mathrm{p}=0.001)$ and TC $(\mathrm{p}<0.001)$ levels were significantly lower, while the TG levels were significantly higher $(\mathrm{p}<0.001)$ compared with healthy subjects. No differences were found between the two groups based on age, blood pressure, height, weight, or BMI, and none had HT. Furthermore, the CACS along with the proportion of minimal-to-mild $(C A C S=1-100)$ and moderate-to-severe (CACS $\geq 101$ ) coronary calcium deposition did not differ significantly between the two groups ( $\mathrm{p}=0.519$ and 0.242 , respectively). Moreover, the cumulative probability plot presented in Figure 1 showed no divergence of the CACS between the two groups.

The subjects who had a CACS of $>0$ were significantly older $(\mathrm{p}=0.002)$ and had higher serum glucose $(\mathrm{p}=0.035)$ and TG $(\mathrm{p}=0.038)$ levels combined with an increased BMI $(\mathrm{p}=0.043)$ compared with those with a CACS of 0 (Table 3 ). In a stepwise

Table 1. Clinical characteristics of the patients with systemic sclerosis

\begin{tabular}{|c|c|c|c|c|c|c|c|c|c|c|c|c|c|c|c|}
\hline & \multicolumn{5}{|c|}{ Total $(\mathrm{n}=41)$} & \multicolumn{5}{|c|}{ Limited SSc patients $(n=20)$} & \multicolumn{5}{|c|}{ Diffuse SSc patients $(n=21)$} \\
\hline & $\mathrm{n}$ & $\%$ & Mean \pm SD & Median & Min.-max. & $\mathrm{n}$ & $\%$ & Mean \pm SD & Median & Min.-max. & $\mathrm{n}$ & $\%$ & Mean \pm SD & Median & Min.-max. \\
\hline Age (years) & & & $50.1 \pm 11.6$ & & & & & $52.1 \pm 12.7$ & & & & & $48.1 \pm 10.4$ & & \\
\hline Disease duration (years) & & & & 6 & $1-33$ & & & & 5.5 & $1-33$ & & & & 6 & $1-30$ \\
\hline \multicolumn{16}{|l|}{ Organ involvement } \\
\hline Interstitial lung disease & 29 & 70.7 & & & & 13 & 65 & & & & 16 & 76.2 & & & \\
\hline PAH & 3 & 7.3 & & & & 1 & 5 & & & & 2 & 9.5 & & & \\
\hline Gastrointestinal tract & 32 & 78 & & & & 16 & 80 & & & & 16 & 76.2 & & & \\
\hline Modified Rodnan skin score & & & $13.0 \pm 7.4$ & & & & & $7.2 \pm 4.2$ & & & & & $18.7 \pm 4.8^{*}$ & & \\
\hline ESR $(\mathrm{mm} / \mathrm{hr})$ & & & & 31 & $2-120$ & & & & 24 & $3-85$ & & & & 34.5 & $2-120$ \\
\hline C-reactive protein (mg/dl) & & & & 0.11 & $0-2$ & & & & 0.08 & $0-1.4$ & & & & 0.15 & $0-2.0$ \\
\hline \multicolumn{16}{|l|}{ Current medication } \\
\hline Pencillamine & 24 & 58.5 & & & & 11 & 55 & & & & 13 & 61.9 & & & \\
\hline Cyclophosphamide $\ddagger$ & 17 & 41.4 & & & & 6 & 30 & & & & 11 & 52.4 & & & \\
\hline Vasodilator $\$$ & 33 & 80.5 & & & & 17 & 85 & & & & 16 & 76.2 & & & \\
\hline Anti-platelet agent & 29 & 70.7 & & & & 14 & 70 & & & & 15 & 71.4 & & & \\
\hline Glucocorticoids & 27 & 65.9 & & & & 13 & 65 & & & & 14 & 66.7 & & & \\
\hline Cumulative GCs dose (g) & & & & 0.91 & $0-1.11$ & & & & 0.28 & $0-5$ & & & & 1.87 & $0-11.08$ \\
\hline \multicolumn{16}{|l|}{ Positive antibodies } \\
\hline Antinuclear antibody & 41 & 100 & & & & 20 & 100 & & & & 21 & 100 & & & \\
\hline Anti-Scl-70 & 16 & 39 & & & & 2 & 10 & & & & 14 & $66.7^{\star}$ & & & \\
\hline Anticentromere antibody & 6 & 14.6 & & & & 4 & 20 & & & & 2 & 10.5 & & & \\
\hline
\end{tabular}




\begin{tabular}{|c|c|c|c|c|c|c|c|c|c|c|c|}
\hline & \multicolumn{5}{|c|}{ SSc patients $(n=41)$} & \multicolumn{5}{|c|}{ Healthy controls $(n=123)$} & \multirow[b]{2}{*}{$p$} \\
\hline & $\mathrm{n}$ & $\%$ & Mean \pm SD & Median & Min.-max. & $\mathrm{n}$ & $\%$ & Mean \pm SD & Median & Min.-max. & \\
\hline Age (years) & & & $50.1 \pm 11.6$ & & & & & $51.5 \pm 10.7$ & & & 0.450 \\
\hline SBP (mmHg) & & & $109.5 \pm 12.4$ & & & & & $112.0 \pm 13.8$ & & & 0.310 \\
\hline $\mathrm{DBP}(\mathrm{mmHg})$ & & & $69.0 \pm 9.8$ & & & & & $68.0 \pm 10.3$ & & & 0.593 \\
\hline Serum glucose $(\mathrm{mg} / \mathrm{dl})$ & & & $84.3 \pm 10.0$ & & & & & $92.0 \pm 10.2$ & & & $<0.001$ \\
\hline LDL-C (mg/dl) & & & $106.1 \pm 33.6$ & & & & & $121.9 \pm 30.1$ & & & 0.006 \\
\hline TG (mg/dL) & & & & 123.5 & $(34,277)$ & & & & 91.0 & $(32,243)$ & 0.016 \\
\hline HDL-C (mg/dl) & & & $52.3 \pm 15.8$ & & & & & $61.6 \pm 15.0$ & & & 0.001 \\
\hline $\mathrm{TC}(\mathrm{mg} / \mathrm{dl})$ & & & $174.2 \pm 29.6$ & & & & & $203.5 \pm 30.7$ & & & $<0.001$ \\
\hline Height $(\mathrm{cm})$ & & & $157.5 \pm 4.8$ & & & & & $157.3 \pm 5.3$ & & & 0.820 \\
\hline Weight (kg) & & & $54.3 \pm 7.0$ & & & & & $55.8 \pm 7.3$ & & & 0.262 \\
\hline BMI $\left(\mathrm{kg} / \mathrm{m}^{2}\right)$ & & & $21.9 \pm 2.7$ & & & & & $22.6 \pm 2.9$ & & & 0.193 \\
\hline CACS (score) & & & & 0 & $0-133.5$ & & & & 0 & $0-454.1$ & 0.519 \\
\hline \multicolumn{12}{|l|}{ CACS classification } \\
\hline Absent $\ddagger$ & 34 & 82.9 & & & & 107 & 86.9 & & & & \\
\hline Minimal to milds & 5 & 12.2 & & & & 15 & 12.2 & & & & \\
\hline Moderate to severe & 2 & 4.8 & & & & 2 & 0.8 & & & & \\
\hline
\end{tabular}

multivariable logistic regression analysis, SSc was not independently associated with the presence of coronary calcium deposition (CACS $>0$ ) after adjustments were made for age, serum glucose, TGs, and BMI (Table 4). Furthermore, in a stepwise multivariable ordinal logistic regression model, although the SSc patients were more likely to have a higher category of CACS (OR 2.79; 95\% CI 0.92-8.49; $\mathrm{p}=0.070$ ) compared with the healthy controls after adjusting for age, serum glucose, and TGs, this did not reach statistical significance (Table 4). However, older age was an independent risk factor for coronary calcium deposition in the logistic

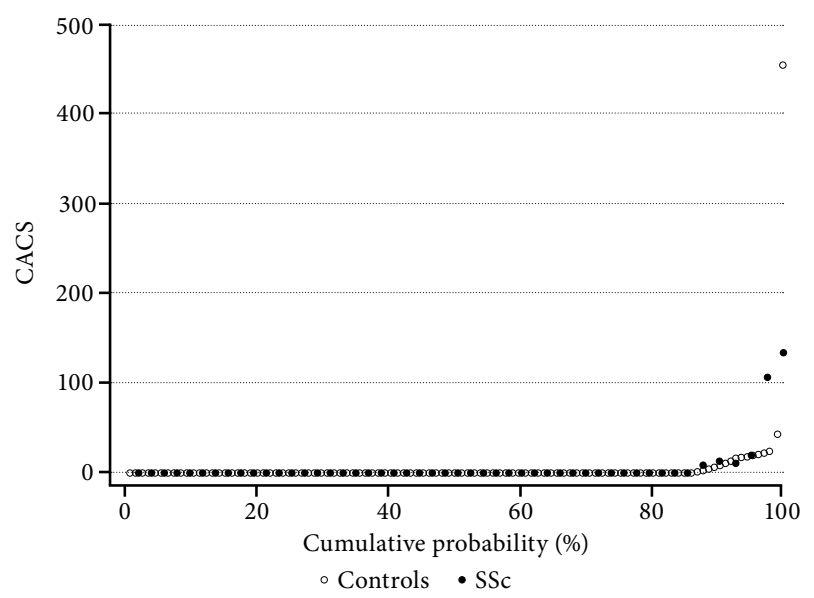

Figure 1. Probability plot of the coronary artery calcium scores (CACS) showing both the systemic sclerosis (SSc) patients and healthy controls. regression models for both the SSc patients (OR 1.07; 95\% CI 1.01-1.13; $\mathrm{p}=0.007)$ and healthy subjects (OR 1.08; 95\% CI 1.02-1.13; $\mathrm{p}=0.006$ ). In addition, the increased fasting serum glucose levels (OR 1.06; 95\% CI 1.01-1.11; $\mathrm{p}=0.022$ ) showed a significant association with the higher category of CACS only in the multivariable ordinal logistic regression model (Table 4).

Subgroup analyses for conventional risk factors and the CACS were also performed on the patients with SSc, and there were no significant differences between the limited and diffuse SSc patients according to the serum glucose, LDL-C, TG, HDL-C, and TC levels or BMI (data not shown). In addition, the CACS and the percentage of higher categories of coronary calcium deposition in the limited SSc patients did not differ significantly from those in the diffuse SSc patients (data not shown).

\section{DISCUSSION}

In the present study, the CACS in the SSc patients, as measured by MDCT, did not differ significantly from the healthy subjects after making adjustments for confounding factors. Among traditional cardiovascular risk factors, older age was significantly associated with increased coronary calcium deposition. Our results suggest that SSc is not an independent risk factor for increased coronary calcium deposition and that SSc patients are not at high risk for atherosclerosis. 
Table 3. A comparison of clinical characteristics of the study population according to the presence or absence of coronary artery calcium deposition

\begin{tabular}{|c|c|c|c|c|c|c|c|}
\hline & \multicolumn{3}{|c|}{ CACS $>0(n=23)$} & \multicolumn{3}{|c|}{$\mathrm{CACS}=0(\mathrm{n}=141)$} & \multirow[b]{2}{*}{$p$} \\
\hline & $\mathrm{n}$ & $\%$ & Mean \pm SD & $\mathrm{n}$ & $\%$ & Mean \pm SD & \\
\hline Age (years) & & & $57 \pm 6.6$ & & & $50.1 \pm 11.2$ & 0.002 \\
\hline Systemic blood pressure (mmHg) & & & $113.8 \pm 16.8$ & & & $111.0 \pm 12.8$ & 0.440 \\
\hline Diastolic blood pressure (mmHg) & & & $67.7 \pm 10.6$ & & & $68.4 \pm 10.2$ & 0.782 \\
\hline Serum glucose $(\mathrm{mg} / \mathrm{dl})$ & & & $95.3 \pm 11.7$ & & & $88.9 \pm 11.3$ & 0.035 \\
\hline Low density lipoprotein cholesterol (mg/dl) & & & $115.4 \pm 33.0$ & & & $118.4 \pm 31.5$ & 0.653 \\
\hline Triglyceride $(\mathrm{mg} / \mathrm{dl})$ & & & $126.4 \pm 54.1$ & & & $102.2 \pm 48.3$ & 0.038 \\
\hline High density lipoprotein cholesterol (mg/dl) & & & $56.4 \pm 9.6$ & & & $59.8 \pm 16.5$ & 0.394 \\
\hline Body mass index $\left(\mathrm{kg} / \mathrm{m}^{2}\right)$ & & & $23.4 \pm 2.7$ & & & $22.3 \pm 2.9$ & 0.043 \\
\hline Number of systemic sclerosis patients & 7 & 30.4 & & 34 & 24.1 & & 0.604 \\
\hline
\end{tabular}

Our study also showed that there were no significant differences related to coronary calcium deposition between the SSc patients and healthy subjects, which is inconsistent with the results of previous reports. ${ }^{[16,17]}$ Khruma et al. ${ }^{[16]}$ indicated that SSc patients have significantly higher rates of subclinical coronary atherosclerosis than healthy controls in terms of the CACS. However, their study only analyzed 17 SSc patients and 17 healthy controls. The small sample size may have skewed their results; thus they should be interpreted with caution. In addition, Mok and $\mathrm{Lau}^{[2]}$ determined that SSc was an independent determinant for a CACS of $\geq 101$ (OR=10.89; 95\% CI=2.21-53.75; $\mathrm{p}=0.02)$ in their multiple logistic regression analysis. The reason for this discrepancy may be due to the difference in the overall severity of coronary atherosclerosis between their study and ours. The number of participants who had a CACS of $\geq 101$ and a CACS of $>0$ was higher in their study than ours $(14.5 \%$ vs. $2.4 \%$ and $29.6 \%$ vs. $14.6 \%$, respectively). This discrepancy could be caused by the differences in the characteristics of the study population. Since those taking lipid, blood pressure or glucose-lowering agents along with current and past smokers were excluded from our study, we included relatively "healthier" subjects than previous studies, and this may have contributed to the lower prevalence of coronary calcium deposition. Hence, our study suggests that compared with healthy subjects, SSc patients with low cardiovascular risk profiles are not associated with increased coronary atherosclerosis, as measured by MDCT.

There have been limited clinical studies concerning the prevalence of cardiovascular disease, including those that have compared coronary heart diseases in SSc patients and healthy controls. In fact, a recent, large cross-sectional study conducted by Ngian et

Table 4. Risk factors for the presence of coronary calcium deposition

\begin{tabular}{|c|c|c|c|c|}
\hline & $\begin{array}{c}\text { Crude OR } \\
(95 \% \text { CI })\end{array}$ & $p$ & $\begin{array}{c}\text { Adjusted OR } \\
(95 \% \mathrm{CI})\end{array}$ & $p$ \\
\hline \multicolumn{5}{|l|}{ Logistic regression model $\dagger$} \\
\hline Age (years) & $1.08(1.03-1.13)$ & 0.003 & $1.07(1.01-1.13)$ & 0.007 \\
\hline Serum glucose $(\mathrm{mg} / \mathrm{dL})$ & $1.06(1.01-1.10)$ & 0.014 & $1.05(1.00-1.10)$ & 0.062 \\
\hline Triglyceride (mg/dL) & $1.01(1.00-1.02)$ & 0.035 & - & - \\
\hline Body mass index $\left(\mathrm{kg} / \mathrm{m}^{2}\right)$ & $1.13(0.98-1.31)$ & 0.094 & - & - \\
\hline Systemic sclerosis versus control & $1.38(0.52-3.63)$ & 0.517 & - & - \\
\hline \multicolumn{5}{|l|}{ Ordinal logistic regression model $\ddagger$} \\
\hline Age (years) & $1.08(1.03-1.13)$ & 0.003 & $1.08(1.02-1.13)$ & 0.006 \\
\hline Serum glucose $(\mathrm{mg} / \mathrm{dL})$ & $1.06(1.01-1.10)$ & 0.015 & $1.06(1.01-1.11)$ & 0.022 \\
\hline Triglyceride (mg/dL) & $1.01(1.00-1.02)$ & 0.036 & - & - \\
\hline Systemic sclerosis versus control & $1.43(0.55-3.78)$ & 0.465 & $2.79(0.92-8.49)$ & 0.070 \\
\hline
\end{tabular}


al. ${ }^{[24]}$ showed that the prevalence of coronary heart disease in SSc patients was three times higher than that of healthy subjects. In addition, Man et al. ${ }^{[25]}$ suggested that SSc is related to an increased risk of myocardial infarction (MI), stroke, and peripheral vascular diseases in their population-based study. In contrast, the results of epidemiological studies using surrogate markers for atherosclerosis, such as carotid-intima media thickness, arterial stiffness, flow-mediated dilatation, and MDCT (as in our study) in SSc patients, were somewhat conflicting. ${ }^{[10,11,16,17]}$ We presume that the complexity in the pathogenesis of cardiovascular diseases in SSc patients provides an explanation for the discrepancies in these findings. Despite atherosclerosis playing a major role in the pathogenesis of cardiovascular diseases, non-atherosclerotic factors, such as vasospasm, thrombosis by inflammation, and endothelial dysfunction, may also contribute to both macrovascular and microvascular diseases in SSc. ${ }^{[11]}$ Thus, the presence of atherosclerosis may play a necessary but insufficient role in the presence of cardiovascular diseases in SSc patients.

Coronary artery calcium scores, as measured by MDCT, are recognized as an indicator of the total coronary atherosclerosis burden and are a robust tool for calculating risk stratification and predicting coronary heart disease. However, CACS are not effective for evaluating a particular stenosis, plaque stability, or non-calcified plaque burden. ${ }^{[14,26-28]}$ Owing to its high specificity, CACS, as measured by MDCT, could be a preferred imaging test for subjects with an intermediate likelihood of significant CAD, but they are not strongly recommended as a screening tool for atherosclerosis in the asymptomatic population. ${ }^{[13,29,30]}$ Considering that the participants in our study were rather asymptomatic, evaluating the CACS in these subjects may not have been appropriate. However, because SSc has been considered to be a risk factor for cardiovascular disease in previous studies, ${ }^{[24,25]}$ measuring the CACS via MDCT in SSc patients may provide valuable information regarding the assessment and prediction of coronary heart disease. In addition, we conjecture that CACS evaluated by MDCT could be applied as a gatekeeper in the workup of SSc patients suspected of having cardiovascular disease.

Among traditional cardiovascular risk factors, age and male gender are the strongest predictors for higher CACS and coronary plaque, as evaluated by MDCT, whereas diabetes mellitus (DM), HT, and dyslipidemia also showed significant associations with coronary calcification. ${ }^{[31-34]}$ We also determined that older age was an independent risk factor for increased coronary calcium deposition, which was consistent with the findings of previous studies. ${ }^{[17,31,33,34]}$ However, other cardiovascular risk factors like blood pressure, serum glucose levels, and dyslipidemia were not statistically significant in our study, but this may have been due to the small sample size. Further research is needed to explore the relationships between SSc-specific factors and coronary calcium deposition.

Although the prevalence of traditional cardiovascular risk factors in patients with SSc has not yet been systematically investigated, recent studies have found no significant differences between SSc patients and healthy controls. ${ }^{[17,24,25]}$ Likewise, in our study, the SSc patients had higher TG, lower serum glucose, LDL-C, and HDL-C levels than the healthy controls, whereas the blood pressure and BMI were similar between the two groups. We assumed that the cardiovascular risk factors of the SSc patients would be approximately the same as those in the healthy subjects, but because we excluded those who were taking lipid, blood pressure or glucoselowering agents from our study, our findings should be interpreted with caution.

Some limitations of our study warrant further discussion. First, due to the small sample size, only female SSc patients were evaluated. In addition, there was no disease control, such as RA or SLE, in our study; therefore, it was not possible to compare coronary atherosclerosis with other rheumatic diseases. Furthermore, as previously mentioned, excluding those who were taking lipid, blood pressure or glucoselowering agents, may have acted as a selection bias. Because these medications are more likely to be given to subjects with intermediate or high cardiovascular risk, our study included subjects with a low risk for cardiovascular diseases. Thus, our results must be considered in light of the characteristics of the study population. Lastly, we did not collect data related to physical activity or functional status, which might have played a role in the prevalence of cardiovascular risk factors, such as obesity and lipid profiles. Since SSc is considered to be a chronic, persistent, disabling disease, it is presumed that the exercise tolerance or physical activity in SSc patients is lower than for healthy subjects. However, we were not able to fully adjust for these factors. 


\section{Conclusion}

In this study, we determined that coronary calcium deposition in patients with SSc does not increase compared with healthy subjects after adjustment for other relevant risk factors. Although our findings should be interpreted with caution due to the retrospective nature of our study and the characteristics of our study participants, our data suggests that SSc is not an independent risk factor for atherosclerosis. However, further research is needed to investigate the relationship between coronary calcium deposition and cardiovascular diseases of patients with SSc in real clinical settings.

\section{Acknowledgement}

We specially thank the late Professor Sung-Il Kim who devoted himself to education, research, and patient care in the Division of Rheumatology, Department of Internal Medicine, Pusan National University School of Medicine (1963-2011).

\section{Declaration of conflicting interests}

The authors declared no conflicts of interest with respect to the authorship and/or publication of this article.

\section{Funding}

This study was supported by the Medical Research Institute Grant (2010-14), Pusan National University Hospital.

\section{REFERENCES}

1. Kahaleh MB. Vascular involvement in systemic sclerosis (SSc). Clin Exp Rheumatol 2004;22:S19-23.

2. Mok MY, Lau CS. The burden and measurement of cardiovascular disease in SSc. Nat Rev Rheumatol 2010;6:430-4.

3. Davignon J, Ganz P. Role of endothelial dysfunction in atherosclerosis. Circulation 2004;109:III27-32.

4. Tyrrell PN, Beyene J, Feldman BM, McCrindle BW, Silverman ED, Bradley TJ. Rheumatic disease and carotid intima-media thickness: a systematic review and metaanalysis. Arterioscler Thromb Vasc Biol 2010;30:1014-26.

5. Au K, Singh MK, Bodukam V, Bae S, Maranian P, Ogawa R, et al. Atherosclerosis in systemic sclerosis: a systematic review and meta-analysis. Arthritis Rheum 2011;63:2078-90.

6. Allanore Y, Meune C. Primary myocardial involvement in systemic sclerosis: evidence for a microvascular origin. Clin Exp Rheumatol 2010;28:S48-53.

7. Symmons DP, Gabriel SE. Epidemiology of CVD in rheumatic disease, with a focus on RA and SLE. Nat Rev Rheumatol 2011;7:399-408.
8. Gasparyan AY, Stavropoulos-Kalinoglou A, Mikhailidis DP, Toms TE, Douglas KM, Kitas GD. The rationale for comparative studies of accelerated atherosclerosis in rheumatic diseases. Curr Vasc Pharmacol 2010;8:437-49.

9. Belch JJ, McSwiggan S, Lau C. Macrovascular disease in systemic sclerosis: the tip of an iceberg? Rheumatology (Oxford) 2008;47 Suppl 5:v16-7.

10. Nussinovitch U, Shoenfeld Y. Atherosclerosis and macrovascular involvement in systemic sclerosis: myth or reality. Autoimmun Rev 2011;10:259-66.

11. Ngian GS, Sahhar J, Wicks IP, Van Doornum S. Cardiovascular disease in systemic sclerosis--an emerging association? Arthritis Res Ther 2011;13:237.

12. Lembcke A, Hein PA, Dohmen PM, Klessen C, Wiese $\mathrm{TH}$, Hoffmann $\mathrm{U}$, et al. Pictorial review: electron beam computed tomography and multislice spiral computed tomography for cardiac imaging. Eur J Radiol 2006;57:356-67.

13. Sun Z, Jiang W. Diagnostic value of multislice computed tomography angiography in coronary artery disease: a meta-analysis. Eur J Radiol 2006;60:279-86.

14. Abdulla J, Asferg C, Kofoed KF. Prognostic value of absence or presence of coronary artery disease determined by 64-slice computed tomography coronary angiography a systematic review and meta-analysis. Int J Cardiovasc Imaging 2011;27:413-20.

15. Arbab-Zadeh A, Miller JM, Rochitte CE, Dewey M, Niinuma H, Gottlieb I, et al. Diagnostic accuracy of computed tomography coronary angiography according to pre-test probability of coronary artery disease and severity of coronary arterial calcification. The CORE-64 (Coronary Artery Evaluation Using 64-Row Multidetector Computed Tomography Angiography) International Multicenter Study. J Am Coll Cardiol 2012;59:379-87.

16. Khurma V, Meyer C, Park GS, McMahon M, Lin J, Singh RR, et al. A pilot study of subclinical coronary atherosclerosis in systemic sclerosis: coronary artery calcification in cases and controls. Arthritis Rheum 2008;59:591-7.

17. Mok MY, Lau CS, Chiu SS, Tso AW, Lo Y, Law LS, et al. Systemic sclerosis is an independent risk factor for increased coronary artery calcium deposition. Arthritis Rheum 2011;63:1387-95.

18. Preliminary criteria for the classification of systemic sclerosis (scleroderma). Subcommittee for scleroderma criteria of the American Rheumatism Association Diagnostic and Therapeutic Criteria Committee. Arthritis Rheum 1980;23:581-90.

19. van Staa TP, Geusens P, Bijlsma JW, Leufkens HG, Cooper C. Clinical assessment of the long-term risk of fracture in patients with rheumatoid arthritis. Arthritis Rheum 2006;54:3104-12.

20. LeRoy EC, Black C, Fleischmajer R, Jablonska S, Krieg T, Medsger TA Jr, et al. Scleroderma (systemic sclerosis): classification, subsets and pathogenesis. J Rheumatol 1988;15:202-5. 
21. Amjadi S, Maranian P, Furst DE, Clements PJ, Wong WK, Postlethwaite AE, et al. Course of the modified Rodnan skin thickness score in systemic sclerosis clinical trials: analysis of three large multicenter, doubleblind, randomized controlled trials. Arthritis Rheum 2009;60:2490-8.

22. Agatston AS, Janowitz WR, Hildner FJ, Zusmer NR, Viamonte M Jr, Detrano R. Quantification of coronary artery calcium using ultrafast computed tomography. J Am Coll Cardiol 1990;15:827-32.

23. Landewé R, van der Heijde D. Radiographic progression depicted by probability plots: presenting data with optimal use of individual values. Arthritis Rheum 2004;50:699-706.

24. Ngian GS, Sahhar J, Proudman SM, Stevens W, Wicks IP, Van Doornum S. Prevalence of coronary heart disease and cardiovascular risk factors in a national cross-sectional cohort study of systemic sclerosis. Ann Rheum Dis 2012;71:1980-3.

25. Man A, Zhu Y, Zhang Y, Dubreuil M, Rho YH, Peloquin $\mathrm{C}$, et al. The risk of cardiovascular disease in systemic sclerosis: a population-based cohort study. Ann Rheum Dis 2013;72:1188-93.

26. van Werkhoven JM, Bax JJ, Nucifora G, Jukema JW, Kroft LJ, de Roos A, et al. The value of multi-slice-computed tomography coronary angiography for risk stratification. J Nucl Cardiol 2009;16:970-80.

27. Budoff MJ, Gul KM. Expert review on coronary calcium. Vasc Health Risk Manag 2008;4:315-24.

28. Wilson GT, Gopalakrishnan P, Tak T. Noninvasive cardiac imaging with computed tomography. Clin Med Res 2007;5:165-71.

29. Hendel RC, Patel MR, Kramer CM, Poon M, Hendel RC, Carr JC, et al. ACCF/ACR/SCCT/SCMR/ASNC/NASCI/ SCAI/SIR 2006 appropriateness criteria for cardiac computed tomography and cardiac magnetic resonance imaging: a report of the American College of Cardiology Foundation Quality Strategic Directions Committee Appropriateness Criteria Working Group, American College of Radiology, Society of Cardiovascular Computed Tomography, Society for Cardiovascular Magnetic Resonance, American Society of Nuclear Cardiology, North American Society for Cardiac Imaging, Society for Cardiovascular Angiography and Interventions, and Society of Interventional Radiology. J Am Coll Cardiol 2006;48:1475-97.

30. ASCI CCT \& CMR Guideline Working Group, Tsai IC, Choi BW, Chan C, Jinzaki M, Kitagawa K, et al. ASCI 2010 appropriateness criteria for cardiac computed tomography: a report of the Asian Society of Cardiovascular Imaging Cardiac Computed Tomography and Cardiac Magnetic Resonance Imaging Guideline Working Group. Int J Cardiovasc Imaging 2010;26 Suppl 1:1-1.

31. Allison MA, Wright CM. Age and gender are the strongest clinical correlates of prevalent coronary calcification (R1). Int J Cardiol 2005;98:325-30.

32. Nasir K, Vasamreddy C, Blumenthal RS, Rumberger JA. Comprehensive coronary risk determination in primary prevention: an imaging and clinical based definition combining computed tomographic coronary artery calcium score and national cholesterol education program risk score. Int J Cardiol 2006;110:129-36.

33. Rivera JJ, Nasir K, Cox PR, Choi EK, Yoon Y, Cho I, et al. Association of traditional cardiovascular risk factors with coronary plaque sub-types assessed by 64-slice computed tomography angiography in a large cohort of asymptomatic subjects. Atherosclerosis 2009;206:451-7.

34. Park HE, Kim MK, Choi SY, Lee W, Shin CS, Cho $\mathrm{SH}$, et al. The prevalence and distribution of coronary artery calcium in asymptomatic Korean population. Int J Cardiovasc Imaging 2012;28:1227-35. 